\title{
A Prática Educativa Docente sobre o Projeto Político Pedagógico: Relato de Experiência junto à Pós-Graduação em Enfermagem
}

\author{
Anna Maria Meyer Maciel Rodríguez ${ }^{1^{*}}$, Larissa Karoline Dias da Silva Cassemiro², Letícia \\ Lopes Dorneles ${ }^{3}$, Mariana Vitor Peppe ${ }^{4}$, Marlene Fagundes Carvalho Gonçalves ${ }^{5}$, Cinira \\ Magali Fortuna ${ }^{6}$, Maria José Clapis ${ }^{7}$ \\ ${ }^{1}$ Enfermeira, doutoranda do Programa de Pós-Graduação em Enfermagem em Saúde Pública da Escola de \\ Enfermagem de Ribeirão Preto da Universidade de São Paulo; \\ ${ }^{2}$ Enfermeira, mestre em Ciências pela EERP-USP \\ ${ }^{3}$ Enfermeira, mestre em Ciências pela EERP-USP, professora contratada 2 do Departamento de Enfermagem \\ Materno-Infantil e Saúde Pública da EERP-USP \\ ${ }^{4}$ Enfermeira, mestre em Ciências pela EERP-USP \\ ${ }^{5}$ Pedagoga, professora associada 1 do Departamento de Enfermagem Psiquiátrica e Ciências Humanas da EERP-USP \\ ${ }^{6}$ Enfermeira, professora associada 1 do Departamento de Enfermagem Materno-Infantil e Saúde Pública da EERP-USP \\ ${ }^{7}$ Enfermeira, professora associada 3 do Departamento de Enfermagem Materno-Infantil e Saúde Pública da EERP-USP
}

* Autoras para correspondência: nimeyer5@hotmail.com, laryssakaroline@hotmail.com, leticia_dorneles@usp.br, marianapeppe@hotmail.com, mgoncalves@eerp.usp.br, fortuna@eerp.usp.br, maclapis@eerp.usp.br

\section{RESUMO}

O objetivo deste estudo foi relatar a experiência de pós-graduandas na elaboração e aplicação de uma prática educativa sobre o Projeto Político Pedagógico (PPP), adequado ao ensino de graduação, utilizando metodologias ativas de ensino-aprendizagem. A atividade foi apresentada para pós-graduandos no contexto de uma disciplina de pós-graduação, sob orientação das docentes responsáveis. A aula ocorreu em 2015, teve a duração de três horas, contou com a participação de 35 pós-graduandos e teve como proposta desenvolver nos alunos condições de conceituar o PPP; entender sua importância, seus princípios e estrutura; compreender os processos que envolvem a sua elaboração e desenvolver pensamentos críticos e reflexivos sobre os desafios de sua implementação nas instituições de ensino. A aula foi desenvolvida em três etapas. Na primeira, disponibilizou-se aos alunos um texto com uma situação-problema fictícia que tratava da elaboração de um PPP para resolver dificuldades de uma instituição de ensino. Na segunda, adaptou-se a metodologia da Aprendizagem Baseada em Problemas (ABP) ao objetivo proposto, buscando os conhecimentos prévios dos alunos acerca do PPP. E na terceira, utilizaramse tarjas de cartolina que continham as etapas de construção de um PPP, para que os alunos as discutissem e as dispusessem em sequência correta. A atividade foi avaliada como satisfatória. Para as pós-graduandas, a experiência de planejar e aplicar metodologias ativas no contexto de ensino-aprendizagem possibilitou: compreender a relevância de um PPP, construir coletivamente sua concepção e desenvolver a formação docente.

Palavras-Chave: Aprendizagem; Metodologias Ativas, Aprendizagem Baseada em Problemas; Educação Superior; Ensino.

\begin{abstract}
The objective of this study was to report the experience of postgraduates in the elaboration and application of an educational practice on the Pedagogical Political Project (PPP), suitable for undergraduate education, using active teaching-learning methodologies. The activity was presented to postgraduate students in the context of a postgraduate course, under the guidance of the responsible professors. The class took place in 2015 , lasted three hours, with the participation of 35 postgraduate students and had as a proposal to develop in the students conditions to conceptualize the PPP; understand its importance, its principles and structure; understand the processes involved in its elaboration and develop critical and reflective thoughts about the challenges of its implementation in educational institutions. The class was developed in three stages. In the first, the students were given a text with a fictitious problem situation that dealt with the elaboration of a PPP to solve difficulties of an educational institution. In the second, the methodology of Problem-Based Learning (PBL) was adapted to the
\end{abstract}


proposed objective, seeking the previous knowledge of the students about the PPP. And in the third one, strips of card that contained the steps of construction of a PPP were used, so that the students discussed them and arranged them in correct sequence. The activity was evaluated as satisfactory. For postgraduate students, the experience of planning and applying active methodologies in the teaching-learning context made it possible to: understand the relevance of a PPP, to constructively construct its conception and to develop teacher training.

Keywords: Learning; Active Methodologies; Problem-Based Learning; Education Higher; Teaching.

\section{Introdução}

O Projeto Político Pedagógico (PPP) é um documento que orienta as atividades de ensino, pesquisa e extensão oferecidas em instituições de ensino, em consonância com a Lei de Diretrizes e Bases da Educação Nacional. No ensino superior, o PPP pode especificar o perfil profissional que a instituição pretende formar, as características gerais, os objetivos, a proposta pedagógica e o currículo do curso (MASETTO, 2003) e, ao mesmo tempo, essas dimensões definem o papel político e social da entidade na sociedade (VASCONCELLOS, 2008). Nesse sentido, o PPP deve permitir a contribuição de todos os sujeitos integrantes da organização de ensino, adquirindo uma representatividade coletiva e ativa em sua construção (MASETTO, 2003; VASCONCELLOS, 2008).

Veiga (2002) compreende o PPP como a própria organização do trabalho pedagógico da escola, que vai além de um simples agrupamento de planos de ensino e de atividades diversas, retratando um compromisso definido coletivamente para atender os interesses reais e coletivos da instituição e com a formação do cidadão. Ele se constitui em um processo democrático de decisões que estabelece as ações educativas e as características necessárias à organização do trabalho pedagógico, buscando eliminar os problemas e propiciar uma qualidade de ensino para todos (VEIGA, 2002).

Na direção de uma condução ativa e compartilhada para se produzirem saberes, apresentam-se as metodologias ativas no processo de ensino -aprendizagem que podem contribuir, também, para o pensar crítico e reflexivo do estudante de nível universitário nas diferentes áreas de atuação (BORGES \& ALENCAR, 2014). Segundo Heck, Jardim, Dilélio e Silva (2009), a metodologia ativa é um processo construtivo de ação-reflexão-ação que enfatiza a crítica, discussão e troca de conhecimentos e não apenas a descrição de conceitos. A utilização desse recurso didático pode favorecer a autonomia do educando, despertando a curiosidade, estimulando tomadas de decisões individuais e coletivas, oriundas das atividades essenciais da prática social e em contextos do estudante (BORGES \& ALENCAR, 2014).

Dadas a relevância do PPP e a adoção de estratégias ativas educacionais para o processo de formação profissional, as docentes responsáveis por uma das disciplinas, que prepara pedagogicamente os pós-graduandos para a atividade docente, propuseram a um grupo de alunas elaborar e aplicar uma prática pedagógica sobre o tema, adequada ao ensino de graduação, aos demais colegas da disciplina de pós-graduação da Escola de Enfermagem de Ribeirão Preto da Universidade de São Paulo (EERP-USP) - que será retratada neste relato de experiência.

\section{Objetivo}

O propósito deste texto é relatar a experiência de pós-graduandas na elaboração e aplicação de uma prática educativa sobre o PPP utilizando metodologias ativas de ensino-aprendizagem, para pós-graduandos, a fim de auxiliá-los na construção coletiva do conhecimento sobre um PPP, bem como no desenvolvimento do pensar crítico -reflexivo sobre os processos que envolvem a sua implantação e implementação nas instituições de ensino superior.

\section{Metodologia}

Trata-se de um relato de experiência sobre a aplicação de metodologias ativas de aprendizagem 
durante a ministração de uma aula sobre PPP, no contexto da disciplina Docência no Ensino da Saúde: Saberes e Práticas, ministrada no curso de pós-graduação em enfermagem da EERP-USP, sob a orientação das docentes responsáveis. A disciplina segue uma proposta de qualificar profissionais para a prática docente na educação superior dos cursos da saúde, possibilitando que os participantes façam reflexões sobre o ensino em cursos de graduação, especialização ou pós-graduação e apropriem-se de conteúdos pertinentes à docência e aspectos relacionados ao ensino, a partir da leitura e discussões de textos, trocas de experiências e participação ativa nas aulas ministradas.

A aula sobre PPP ocorreu no mês de abril de 2015 , teve a duração de três horas, contou com a participação de 35 pós-graduandos e teve como objetivos desenvolver nesses alunos condições de: conceituar o PPP; entender sua importância, seus princípios e estrutura; compreender os processos que envolvem a sua elaboração e propiciar pensamentos críticos e reflexivos sobre os desafios de sua implementação nas instituições de ensino.

\section{Resultados}

Com o compromisso de aplicar uma aula sobre o PPP, adequado ao ensino de graduação, o grupo de alunas se reuniu pessoalmente para pactuar o recurso didático - que se enquadrasse em metodologias ativas de ensino - a ser utilizado nesse cenário. Como uma das integrantes do grupo se aproximou da ABP (aprendizagem baseada em problemas) durante sua formação profissional, sugeriu que fosse aplicada uma adaptação dessa técnica, especialmente pelo tempo de duração da aula. Originalmente, a ABP apresenta um problema pré-formulado aos alunos para que eles aprofundem, individualmente, seu conhecimento sobre um tema obrigatório do currículo e oferece um grupo tutorial de apoio para discutir, em grupo, o saber adquirido (BERBEL, 1998).

Acatada a sugestão, o grupo se encontrou outras três vezes para discutir e definir os aspectos operacionais da aula, tais como: as funções de cada integrante durante o desenvolvimento da proposta, o tempo para cada uma das atividades e a postura das ministrantes frente a possíveis e previsíveis questionamentos e atitudes dos demais colegas da turma.

Para atingir os objetivos propostos e contemplar os itens acima mencionados, as pós-graduandas confeccionaram, inicialmente, um plano de aula para organizar e nortear as ações em sala de aula (CASTRO, TUCUNDUVA \& ARNS, 2008). Esse instrumento apresentava os dados da instituição; o tema abordado, os objetivos e o desenvolvimento da temática; os recursos didáticos que seriam utilizados; a forma de avaliação da aula e as referências bibliográficas indicadas para leitura prévia dos alunos. Definidos esses pontos, o grupo contou com as sugestões das docentes especialmente quanto à clareza na comunicação, organização e síntese das etapas do plano de aula.

O desenvolvimento da temática aconteceu em três fases. Na primeira, criou-se uma situação -problema fictícia que foi impressa e entregue aos alunos da turma. Em seguida, solicitou-se a um voluntário que lesse o texto em voz alta. O texto retratava a elaboração de um PPP para auxiliar na resolução de problemas vivenciados em um determinado curso de graduação em enfermagem de uma universidade fictícia no estado do Amazonas.

$\mathrm{Na}$ segunda, adaptando a metodologia $\mathrm{ABP}$ ao objetivo proposto, os alunos foram questionados sobre seus conhecimentos prévios acerca da temática sugerida, tendo como ponto de partida a situação-problema. Diante das respostas, novas perguntas foram feitas para construir o conhecimento crítico-reflexivo a respeito do assunto. Na medida em que os graduandos contestavam as indagações, todos os aspectos mencionados foram anotados no quadro branco, facilitando a síntese do tema.

Na terceira fase, foram dispostas aleatoriamente no chão onze tarjas de cartolina, cada uma contendo uma etapa para a construção de um PPP, sendo elas: surgimento da necessidade do projeto; decisão inicial de realizá-lo; trabalho de sensibilização e preparação; decisão coletiva; elaboração; publicação; realização interativa; avaliação e atualização do diagnóstico; reprogramação anual; avaliação de 
conjunto; reelaboração parcial ou total. Em seguida, foi solicitado que os discentes selecionassem e pegassem uma tarja por vez, seguindo a ordem cronológica dos passos para o processo de produção e implantação de um PPP. Para estimular a participação discente foi fixado no verso de cada tarja um chocolate e, na medida em que se ofereciam para participar da dinâmica, eram premiados com o mesmo.

Ao se utilizar essa técnica de construção do PPP a partir de tarjas, observou-se que a maioria dos alunos participou ativamente do trabalho apresentado, emitindo opiniões que promoveram discussão e criação coletiva do percurso de construção de um PPP. No final da atividade cada aluno avaliou a aula, as ministrantes e a sua própria participação em: excelente, bom ou regular. As respostas foram assinaladas no quadro e tabuladas e, diante destas respostas, foi possível levantar os pontos positivos e negativos da aula ministrada.

\section{Conclusão}

Apesar de a aula sobre o PPP ter sido planejada para graduandos, a proposta foi ministrada na pós-graduação. Nesse público, havia uma parcela significativa de docentes de outras instituições de ensino que já tiveram a oportunidade de elaborar e implementar um PPP em alguns cursos de graduação. Por essa razão, as colocações discentes apresentaram um caráter empírico, fazendo da aula um espaço valioso de troca de experiências positivas e de dificuldades encontradas na construção coletiva do PPP. Por outro lado, os pós-graduandos não docentes também se posicionaram, trazendo ideias e sugerindo condutas para o enfrentamento dos obstáculos apresentados pelos colegas. Dessa forma, acreditamos que a interação discente pode ter estimulado a reflexão crítica e contribuído para a ampliação dos saberes e o crescimento profissional de todos os alunos da turma.

Ao final da atividade, os pós-graduandos e as docentes responsáveis pela disciplina avaliaram a didática adotada, a postura das ministrantes e a participação discente como satisfatórias. Para as pós-graduandas, a experiência de conviver para planejar e aplicar, em grupo, a ABP, como recurso de prática docente junto aos colegas da turma, possibilitou a compreensão da relevância do tema, aprofundando a bagagem teórico-pedagógica sobre o PPP, para além das referências bibliográficas indicadas pela disciplina - especialmente ao ressaltar, valorizar e compartilhar os saberes prévios e as vivências dos colegas.

A proposta da $\mathrm{ABP}$ e a forma de condução da disciplina estreitaram os laços entre as ministrantes da aula, as docentes e os demais colegas, aprimorando, dessa forma, o aprender a conhecer, o aprender a fazer e o aprender a viver juntos (DELORS, 2001). Assim, consideramos que essa prática concorreu tanto para a concepção discente de um PPP, quanto para o exercício da formação docente das pós-graduandas.

\section{Referências Bibliográficas}

BERBEL, Neusi Aparecida Navas. "A Problematização e a Aprendizagem Baseada em Problemas: Diferentes Termos ou Diferentes Caminhos?". Interface Comunic, Saúde, Educ., Botucatu, vol. 2, n. 2, pp. 139-154, fev. 1998.

BORGES, Tiago Silva \& ALENCAR, Gidélia. "Metodologias Ativas na Promoção da Formação Crítica do Estudante: o Uso de Metodologias Ativas como Recurso Didático na Formação Crítica do Estudante do Ensino Superior". Cairu Rev., Salvador, ano 3, n. 4, pp. 119-143, jul./ago. 2014.

CASTRO, Patricia Aparecida Pereira Penkal de; TUCUNDUVA, Cristiane Costa \& ARNS, Elaine Mandelli. "A Importância do Planejamento das Aulas para Organização do Trabalho do Professor em sua Prática Docente". Rev Cient Educ, Curitiba, vol. 10, n. 10, pp. 49-62, jan./jun. 2008.

DELORS, Jacques. Educasão: um Tesouro a Descobrir. São Paulo: Cortez/MEC/Unesco, 2001.

HECK, Rita Maria; JARDIM, Vanda da Rosa; DILÉLIO, Alitéia Santiago \& SILVA, Solange José da. "Uso de Metodologia Ativa na Disciplina Gerenciamento de Enfermagem em Saúde Coletiva da FEO/UFPEL". Rev. Eletrônica Enferm., Goiânia, vol. 11, n. 2, pp. 429-434, 2009.

MASETTO, Marcos Tarcísio. Competência Pedagógica do Professor Universitário. São Paulo: Summus, 2003.

VASCONCELLOS, Celso dos Santos. Planejamento: Projeto de Ensino-Aprendizagem e Projeto Político-Pedagógico. 18 ed. São Paulo: Libertad, 2008.

VEIGA, Ilma Passos Alencastro. Projeto Politico-Pedagógico da Escola: uma Construção Possível. 14 ed. Papirus, 2002.

Publicado em 22/12/2017. 